Draft 28 April, 2010

\title{
Obesity, Affluence and Urbanisation in India
}

\author{
Raghav Gaiha \\ Faculty of Management Studies \\ University of Delhi \\ Raghbendra Jha \\ Australia South Asia Research Centre \\ Australian National University \\ Canberra \\ \& \\ Vani S. Kulkarni \\ South Asian Studies \\ Yale University
}

Keywords: Obesity, Affluence, Socio-economic characteristics, Gender, India JEL Classification Codes: C25, D12, D31, E10.

All correspondence to:

Prof. Raghbendra Jha,

Australia South Asia Research Centre,

College of Asia and the Pacific

H.C. Coombs Building (09)

Australian National University,

Canberra, ACT 0200, Australia

Phone: + 6126125 2683; Fax: + 6126125 0443; Email: r.jha@anu.edu.au 


\title{
Obesity, Affluence and Urbanisation in India
}

\begin{abstract}
Based on data collected from a representative national sample, India Human Development Survey 2005, this paper investigates the links between obesity among children and among adults with a number of socio economic characteristics as well as household and location specific variables. Both child and adult obesity are far from negligible, which is a matter of concern, given the links between obesity and some diseases. There are strong links between socio-economic indicators and risk of obesity. In particular, affluence has a robust link to obesity. Among children, taller children in more affluent households are more prone to obesity. Some demographic characteristics matter too, for example, both child and adult obesity rise with age but at a diminishing rate. Location also influences chances of obesity. Relative food price effects matter too through calorie, protein, fat and other nutrient intakes. A number of policy conclusions are also advanced.
\end{abstract}




\section{Obesity, Affluence and Urbanisation in India ${ }^{1}$}

\section{Introduction}

Estimates of obesity are alarming. Recent projections indicate that globally in 2005 about 1.6 billion (age $15+$ ) were overweight and at least 400 million were obese. Besides, at least 20 million children under the age of 5 years are overweight globally. By 2015, 2.3 billion adults are likely to be overweight and more than 700 million will be obese. Once considered a problem only in high-income countries, overweight and obesity are emerging as a major health concern in low and middle-income countries (WHO, 2006). ${ }^{2}$

Overweight and obesity are a manifestation of energy imbalance between calories consumed and calories expended. Broadly, the underlying causal factors include (i) dietary shifts towards higher intake of energy-dense foods that are high in fat and sugars but low in vitamins, minerals and other micronutrients; (ii) decreased physical activity due to increasingly sedentary nature of many forms of work, faster; and (iii) less strenuous modes of transportation, and growing urbanisation.

Overweight and obesity are associated with higher risks of cardiovascular disease (mainly heart disease and stroke), diabetes, musculoskeletal disorders-especially osteoarthritis-and some cancers (endometrial, breast and colon). ${ }^{3}$ Childhood obesity, on the other hand, is associated with a higher risk of premature death and disability in adulthood.

Many developing countries are confronted by a ‘double burden’ of malnutrition in which under-nutrition and obesity exist side-by-side within the same country, same community and, not infrequently, in the same household (Kulkarni and Gaiha, 2010). This double burden is attributable to inadequate pre-natal, infant and child nutrition followed by exposure to highfat, energy-dense, micronutrient-deficient foods and lack of physical activity (WHO, 2006; Caballero, 2005). ${ }^{4}$

\footnotetext{
${ }^{1}$ This study was funded by the British Government, under the Foresight Global Food and farming Futures Project. It has benefited from the advice of L. Haddad, A. Venkatraman, Anil Deolalikar, Sonal Desai and J. Murasko. The econometric analysis was carried out competently by Raj Bhatia and Manoj Pandey. We alone are responsible for the views expressed here.

${ }^{2}$ For selected countries in Asia, Middle East and Africa, see Prentice (2005). In China, among adults $>20$ years 3 per cent were obese in 1999-2000; in India, 0.5 per cent of adults>18 years were obese in 1998; and in the Philippines, about 3 per cent of adults $>20$ years were obese in 1998 .

${ }^{3}$ For a recent investigation with a household survey for India, see Gaiha et al. (2010).

${ }^{4}$ For two important recent contributions focused on this double burden among women in India, see Subramanian et al. (2007) and Ackerson et al. (2008). A particularly interesting finding is its robust
} 
The objective of the present study is to assess the prevalence of obesity among children and adults, and the underlying causal factors. These include age, gender, height, caste, household size, educational attainments, location, a measure of standard of living, type of kitchen, access to safe drinking water, who has most say in cooking, and food preferences conditional on relative prices. ${ }^{5}$

The plan of this paper is as follows. In section II we describe salient features of the household survey on which the analysis is based. This is followed, in section III, by a discussion of key correlates of obesity, based on cross-classifications. Building on it, a probit analysis is carried out in section IV to assess the factors associated with obesity among children (2-11 years) and adults ( $>22$ years). Finally, section V offers some concluding observations from a broad policy perspective.

\section{Data}

Our analysis is based on a nationwide household survey, India Human Development Survey 2005 (IHDS), conducted jointly by University of Maryland and National Council of Applied Economic Research (NCAER).

IHDS covers over 41000 households residing in rural and urban areas, selected from 33 states. ${ }^{6}$ The sample comprises 384 districts out of a total of 593 identified in 2001 census. Villages and urban blocks constituted the primary sampling unit from which households were selected.

The rural sample contains about half the households that were interviewed initially by NCAER in 1993-94 in a survey entitled Human Development Profile of India (HDPI) and the other half of the sample households was drawn from both districts surveyed in HDPI as well as from districts located in the states and union territories not covered in HDPI. The original HDPI was a random sample of 33,230 households, located in 16 major states, 195 districts and 1765 villages. In states where the 1993-94 survey was conducted and re-contact

confirmation of an association between state income inequality and level of nutritional status, after controlling for the effects of a range of individual and state level covariates. The adverse contextual effect of state inequality is observed for the risk of being underweight as well as for each of the categories that characterise over-nutrition. More specifically, the context of inequality is found to accentuate the income based disparities in consumption (reflected in individuals’ BMI). Two caveats, however, are necessary. (i) Endogeneity of income inequality is not addressed. (ii) The process through which income inequality impacts on different categories of nutrition is conjectural and thus subject to validation.

${ }^{5}$ For two recent studies focusing on the role of food prices, see Powell and Chaloupka (3009) and Goldman et al. (2010).

${ }^{6}$ This is a summary of the material provided by Sonal Desai. 
details were available, 13593 households were randomly selected for re-interview in 2005. About 82 per cent of the households were contactable for re-interview resulting in a resurvey of 11,153 original households as well as 2,440 households which had separated from the original households but were still living in the same village.

In each district where re-interviews were conducted, two fresh villages were randomly selected using a probability proportional to size technique. In each village, 20 randomly selected households were selected. Additionally, 3,993 households were randomly selected from the states where the 1993-94 survey was not conducted, or where re-contact information was not available.

In order to draw a random sample of urban households, all urban areas in a state were listed in the order of their size with number of blocks drawn from each urban area allocated based on probability proportional to size. After determining the number of blocks, the enumeration blocks were selected randomly. From these enumeration blocks (of about 150-200 households), a complete household listing was obtained and a sample of 15 households was selected per block.

Comparison of IHDS data with the National Sample Survey or NSS (2004-05), National Family Health Survey III (2005-06) and Census (2001) confirms the robustness of IHDS data. For example, IHDS sample distribution on urban residence, caste and religion is remarkably similar to NSS and NFHS-III, although all three surveys (IHDS, NSS and NFHS) have higher proportions of households claiming Scheduled Caste status than enumerated in Census (2001).

\section{Correlates of Obesity}

Overweight and obesity denote abnormal or excessive fat accumulation that may impair health.

Body mass index (BMI) refers to a simple index of weight-for-height $\left(\mathrm{kg} / \mathrm{m}^{2}\right)$ that is widely used in classifying adults as overweight or obese. The WHO defines 'overweight' as a BMI equal to or more than 25, and 'obesity' as a BMI equal to or more than 30 . These cut-off points provide a benchmark for individual assessment but there is evidence that the risk of chronic disease in populations increases progressively from a BMI of 21 (WHO, 2006). 
Although BMI charts exist for infants and young children, measurement of obesity is a challenging task as there is no standard definition of childhood obesity. Accordingly, we follow Murasko (2009) in classifying children whose BMI exceeds the $95^{\text {th }}$ percentile value as obese. ${ }^{7}$

Let us first consider some correlates of obesity among children. These correlates reflect socio-economic conditions-including location. The objective is a broad brush treatment of prevalence of obesity in different age-groups, by gender, caste, poverty status and location. This serves as the backdrop to a more detailed probit analysis.

\section{(a) Children}

Table 1 shows that among the obese in this age-group (2-11years) the share of boys was much higher (over 52 per cent as against 47.77 per cent for girls). ${ }^{8}$ Considering a disaggregated classification Table 2 shows that the share of obese children in the age group 6-11 years was higher (over 51 per cent). This disaggregated classification by gender in Table 3 shows that the shares of obese girls do not vary between the two age-groups. But, Table 4 shows that among the obese boys, the share of older boys is higher. If we consider the poverty status of a household, the contrast is striking. As shown in Table 5, the proportion of non-poor obese children is more than twice as high as that of the poor. This suggests that affluence and obesity are linked.

\section{Tables 1 to 5 here}

In Table 6, a disaggregation of obesity by caste is given. If we go by their economic status, the most poverty prone are the Scheduled Tribes (STs), followed by the SCs (Scheduled Castes), then the OBCs (Other Backward Classes). The results in Table 6 show that the highest proportion of obese children are in Others, followed by OBCs, SCs and then the STs. The considerably lower share of STs is mainly a consequence of their relatively small share in the population.

\section{Table 6 here}

\footnotetext{
${ }^{7}$ So the fractions of children who are obese should be approximately 5 per cent (with small deviations resulting from weighting the numbers by probability weights).

${ }^{8}$ Note that no comment is necessary on the fractions of children in the age-group 2-11 years as small deviations around 5 per cent reflect weighted estimates.
} 
Locationally, the highest proportion of obese children is in rural areas-just under three quarters-followed by urban areas (Table 7). Here again a large part of the difference is due to differences in population shares. However, the fact that the rural share is so much higher implies that prevalence of obesity is not just an urban phenomenon.

\section{Table 7 here}

A related issue is whether these locational differences hold for boys and girls as well. As shown in Tables 8 and 9, both among boys and girls, this pattern is reproduced with only slight differences.

\section{(b) Adults}

The proportion of obese among adults (with BMI > 30) is generally lower than that among children. ${ }^{9}$ The proportion of obese women among adult women is slightly higher than among adult males (Table 10). If adults are classified by age-group, Table 11 shows that the proportion is nearly twice as high among the older age-group (i.e. $>45$ years). However, Table 12 shows that among the obese, a vast majority (over 88 per cent) are in the age-group (23-45 years). ${ }^{10}$

\section{Tables 10, 11 and 12 here}

As among children, the share of obese among adults is more than twice as high as among the poor (Table 13). Also, over 91 per cent of the obese are non-poor. Another proxy for economic status is caste, as stated earlier. The proportion of obese among Others is highest, followed by OBCs and then SCs. Also, more than half of the obese are among Others, followed by OBCs and then SCs (Table 14).

\section{Tables 13 and 14 here}

Locational differences in the prevalence of obesity are striking too, as shown in Table 15. Prevalence of obesity is highest among the urban population, followed by urban slum population. Besides, among the obese, the highest proportion is in urban areas.

\section{Table 15 here}

\footnotetext{
${ }^{9}$ Note that cut-off points are defined differently for children and adults.

${ }^{10}$ Note that the sample of adult males is small as only a few adult males who happened to be around at the time of interview were included. So gender composition of the obese is problematic. We are grateful to Sonal Desai for pointing this out in a personal communication.
} 
To further illustrate the differences in the distributions of obese children and adults in different locations, we have constructed two graphs. Here we classify location of households into rural, urban metros and non-metro urban areas. Figure 1 for obese children shows that the cumulative distribution of obese children in rural areas lies above that for urban metros and the latter lies above that for non-metro urban areas. What is also striking is the steepness of the slopes of these distributions. Figure 2 shows that the cumulative distribution of obese adults in rural areas lies well above those for urban metros and non-metro urban areas-the latter graphs in fact largely overlap. As in the case of obese children distributions, those for obese adults display steep slopes. So the implication is that cumulative proportions of children and adults rise steeply with (log of) per capita expenditure.

In brief, while the prevalence of obesity is low among both children and adults, it is slightly higher among children. ${ }^{11}$ Besides, economic status-or, more specifically, relative affluence and obesity seem to be linked. Finally, prevalence of obesity is high in rural areas for both children and adults-in fact, just under three quarters of the former are located in rural areas.

\section{Figures 1 and 2 here}

As the preceding analysis is largely descriptive- cross-classifications focus on links between specific household characteristics and obesity without controlling for the effects of other factors-we now turn to the probit results. A brief exposition of the probit specification is followed by a discussion of the results.

\section{Probit Specification and results}

In the probit analysis whether a household has an obese person or persons or not is treated as a dichotomous variable. Since our interest is in assessing the associations between obesity and socio-economic factors as well as urban and rural locations, we have employed a probit specification. A brief exposition is given below. ${ }^{12}$

In a binary response model (whether a household has an obese person), interest lies primarily in the response probability:

$$
\mathrm{P}(\mathrm{y}=1 \mid \mathbf{x})=\mathrm{P}\left(\mathrm{y}=1 \mid \mathrm{x}_{1}, \mathrm{x}_{2}, \ldots \ldots \ldots \mathrm{x}_{\mathrm{k}}\right), \ldots \ldots \ldots
$$

where $\mathbf{x}$ denotes the full set of explanatory variables.

\footnotetext{
${ }^{11}$ Recall the caveat about cut-off points for children and adults.

${ }^{12}$ For details, see Wooldridge (2006).
} 
Consider a class of binary response models of the form

$$
P(y=1 \mid x)=G\left(\beta_{0}+x \beta\right)
$$

where $G$ is a function taking on values strictly between zero and one: $0<G(\mathbf{z})<1$, for all real numbers $\mathrm{z}$.

In the probit model, $\mathrm{G}$ is the standard normal cumulative distribution function (cdf).

This analysis is carried out separately for children in the age group 2-11 years, and adults in the age group $>22$ years.

\section{Results}

The probit estimation results for children in the age-group 2-11 years are given in Table 16 .

\section{Table 16 here}

We conclude from Table 16 that child obesity rises with age but at a diminishing rate. Further, girls are less likely to be obese as compared to boys but this result is not very robust. Relative to Others, OBC children are less likely to be obese. Household size and its squaretypically associated with economies of scale in household food expenditure-have no effect on obesity. (Log of) per capita expenditure has a positive effect on child obesity or, more generally, affluence and obesity are positively linked. Height of a child reduces the risk of obesity. However, interaction of expenditure and height has a significant positive effect on obesity. ${ }^{13}$ Somewhat surprisingly, household 'public goods' (e.g. a toilet and access to safe drinking water) have positive effects on child obesity. Also surprising is the absence of a relationship between a mother having most say in cooking and child obesity. A third surprising set of results is the absence of significant relationships between adult male and female educational attainments and child obesity. Further, the type of family (nuclear relative to other types) has an insignificant effect on child obesity. Location, however, matters. Relative to non-metro urban areas, children living in rural areas are less likely to be obese but those living in urban metros are more likely to be obese. The relative prices of food items are of considerable interest. The higher the price of cereals relative to that of, say, pulses, a typical consumer will reduce consumption of cereals and increase consumption of

\footnotetext{
${ }^{13}$ A similar result is reported by Murasko (2009), based on US data. Recent literature emphasizes genetic polymorphisms and the early programming of appetite regulation as determinants of body composition and height growth. Accordingly, researchers have posited that high caloric-intake may drive both height and weight growth in taller children, or that hormonal variations influence stature and body composition. Appetite regulation may also play a role in the allocation of energy intake between fat mass and muscle mass.
} 
pulses. As these substitutions imply different calorie, protein, fat and other nutrient intakes, relative price changes are likely to impact child obesity differently. Our results confirm these effects.

Specifically, the higher the price ratios of cereals/pulses, cereals/milk, cereals/eggs, cereals/vegetables, and cereals/oil, the lower is child obesity. By contrast, the higher the price ratios of cereals/meats, and cereals/sugar, the greater the risk of child obesity.

Turning to the marginal effects, it is noted that the (absolute) effects of per capita expenditure, height, and their interaction are large. Also some of the price effects are large (e.g. cereals/pulses, cereals/meats, cereals/vegetables, cereals/oil and cereals/sugar).

In Table 17 we report results from the probit estimation of adult obesity. The important findings are as follows. The risk of obesity rises with age but at a diminishing rate. Gender, height and marital status are unrelated to the risk of obesity. ${ }^{14}$ The risk of obesity rises with educational years but at a diminishing rate. Obesity and per capita expenditure are positively related. ${ }^{15}$ Adults from SCs, STs and OBCs are less likely to be obese relative to Others. As in the case of child obesity, household toilet is positively related to adult obesity. Location matters too. However, in sharp contrast to child obesity, both rural and urban metros are associated with lower risk of obesity relative to the omitted group of non-metro urban areas. Fewer relative price effects are significant than in the case of child obesity. While higher price ratios of cereals/pulses and cereals/meats lower the risk of adult obesity, that of cereals/milk elevates it.

The corresponding marginal effects are generally small. However, those associated with age, SCs, STs and OBCs, household toilet, rural areas and urban metros, per capita expenditure, and three relative price variables (cereals/pulses, cereals/mil and cereals/meats) are nonnegligible.

\section{Table 17 here}

In Table 18, a slightly different specification is employed. Two changes are: (i) square of (log of) per capita expenditure is used; and (ii) height (along with its interaction with expenditure) is/ are omitted. The results are generally similar with a weakening of the relative price effects.

14 Recall the caveat against the gender effect noted earlier.

15 As log of expenditure and expenditure are monotonically related, 'log' is omitted for expositional convenience. 


\section{Table 18 here}

\section{Concluding Observations}

Some concluding observations are made from a broad policy perspective.

Both child and adult obesity are far from negligible. There are strong links between socioeconomic indicators and risk of obesity. In particular, affluence has a robust link to obesity. Among children, taller children in more affluent households are more prone to obesity. Some demographic characteristics matter too, for example, both child and adult obesity rise with age but at a diminishing rate. Location also influences chances of obesity. What is particularly important is that relative food price effects matter too through calorie, protein, fat and other nutrient intakes.

Policy interventions need to be carefully designed and implemented., as the prospects of halting the obesity pandemic in the near future appear unlikely, if not remote, in communities that have battled for generations to escape abject poverty, bare subsistence and frugal diets. Paradoxically, a more inclusive development may be an important means of breaking out of the poverty-obesity links. Public education campaigns warning of the health consequences of high levels of body fats hold considerable potential for developing countries such as India with a massive expansion of the so-called middle class that is beginning to enjoy westernised diets, fast food, and other life style changes of rapid urbanisation.

As far as dietary changes are concerned, some major imperatives are to limit energy intake from fats, and shift fat consumption away from saturated fats to unsaturated fats, greater consumption of fruits and vegetables, as well as legumes, whole grains and nuts. Sedentary forms of work and life styles of mostly urban and, to a lesser extent, rural populations must give way to more physical activity. Although our analysis of relative price effects is essentially illustrative, it points to the potential of prices in influencing obesity, especially child obesity. Besides, initiatives by the food industry to reduce the fat, sugar and salt content of processed foods and expansion of healthy and nutritious choices may help check this growing epidemic.

In conclusion, while there is now better understanding of policy shifts needed, a nuanced and subtle approach is called for to influence food preferences and choices in a rapidly evolving economic environment and life-style changes. 


\section{References}

Ackerson, L.K., I. Kawachi, E.M. Barbeau and S.V. Subramanian (2008), 'Geography of Underweight and Overweight among Women in India: A Multilevel Analysis of 3204 Neighbourhoods in 26 States', Economics and Human Biology, vol. 6.

Caballero, B. (2005), 'A nutrition Paradox-Underweight and Obesity in Developing Countries', New England Journal of Medicine, April 14.

Gaiha, R., R. Jha and Vani S. Kulkarni (2009), 'Who Has Most Say in Cooking?’, Canberra: ASARC Working Paper 2009/19, Australian National University.

Gaiha, R., R. Jha and Vani S. Kulkarni (2010), 'Affluence, Obesity and Non-Communicable Disease in India’, Canberra: ASARC Working Paper 2010/8, Australian National University.

Goldman, D., D. Lakdawalla and Y. Zheng (2010), 'Food Prices and the Dynamics of Body Weight', mimeo.

Kulkarni, Vani. S. and R. Gaiha (2010), 'Dietary Transition in India', Philadelphia: India in Transition, CASI, University of Pennsylvania, March.

Murasko, J. E. (2009), 'Socioeconomic Status, Height and Obesity in Children', Economics and Human Biology, forthcoming.

Prentice, A.M. (2005), 'The Emerging Epidemic of Obesity in Developing Countries', International Journal of Epidemiology, vol. 35.

Powell, L.M. and F.J. Chaloupka (2009), 'Economic Contextual Factors and Child Body Mass Index', Cambridge:MA, NBER Working paper 15046.

Subramanian, S.V., I. Kawachi and G.D. Smith (2007), 'Income Inequality and the Double Burden of Under and Overnutrition in India', Journal of Epidemiology and Community Health, vol. 61.

WHO (2006), 'Obesity and Overweight', Fact Sheet no. 311, September.

Wooldridge, J.M. (2006), Introductory Econometrics: A Modern Approach, Third Edition, Thompson South-Western. 
Table 1

Prevalence of Obesity among Children 2-11 Years by Gender

\begin{tabular}{|c|c|c|c|}
\hline \multirow{3}{*}{ Gender } & \multicolumn{3}{|c|}{ Obese } \\
\cline { 2 - 4 } & No & Yes & Total \\
\hline \multirow{4}{*}{ Boys } & 13,974 & 733 & 14,707 \\
\cline { 2 - 4 } & 95.01 & 4.99 & 100.00 \\
\cline { 2 - 4 } & 51.94 & 52.23 & 51.95 \\
\cline { 2 - 4 } & 49.36 & 2.59 & 51.95 \\
\hline \multirow{4}{*}{ Girls } & 12,932 & 671 & 13,603 \\
\cline { 2 - 4 } & 95.07 & 4.93 & 100.00 \\
\cline { 2 - 4 } & 48.06 & 47.77 & 48.05 \\
\cline { 2 - 4 } & 45.68 & 2.37 & 48.05 \\
\hline \multirow{4}{*}{ Total } & 26,905 & 1,405 & 28,310 \\
\cline { 2 - 4 } & 95.04 & 4.96 & 100.00 \\
\cline { 2 - 4 } & 100.00 & 100.00 & 100.00 \\
\cline { 2 - 4 } & 95.04 & 4.96 & 100.00 \\
\hline
\end{tabular}

Table 2

Prevalence of Obesity among Children by Age Group

\begin{tabular}{|c|c|c|c|}
\hline \multirow{2}{*}{$\begin{array}{l}\text { Age- Group } \\
\text { (in years) }\end{array}$} & \multicolumn{3}{|c|}{ Obese } \\
\hline & No & Yes & Total \\
\hline \multirow{4}{*}{$2-5$} & 6,845 & 360 & 7,205 \\
\hline & 95.01 & 4.99 & 100.00 \\
\hline & 48.80 & 48.86 & 48.81 \\
\hline & 46.37 & 2.44 & 48.81 \\
\hline \multirow{4}{*}{ 6-11 } & 7,181 & 377 & 7,558 \\
\hline & 95.02 & 4.98 & 100.00 \\
\hline & 51.20 & 51.14 & 51.19 \\
\hline & 48.64 & 2.55 & 51.19 \\
\hline \multirow{4}{*}{ Total } & 14,027 & 736 & 14,763 \\
\hline & 95.01 & 4.99 & 100.00 \\
\hline & 100.00 & 100.00 & 100.00 \\
\hline & 95.01 & 4.99 & 100.00 \\
\hline
\end{tabular}


Table 3

Prevalence of Obesity among Girls by Age Group

\begin{tabular}{|c|c|c|c|}
\hline \multirow{2}{*}{$\begin{array}{c}\text { Age-Group } \\
\text { (in years) }\end{array}$} & \multicolumn{3}{|c|}{ Obese } \\
\cline { 2 - 4 } & No & yes & Total \\
\hline \multirow{4}{*}{$2-5$} & 6,262 & 329 & 6,591 \\
\cline { 2 - 4 } & 95.01 & 4.99 & 100.00 \\
\cline { 2 - 4 } & 48.62 & 49.23 & 48.65 \\
\cline { 2 - 4 } & 46.23 & 2.43 & 48.65 \\
\hline \multirow{4}{*}{$6-11$} & 6,617 & 339 & 6,956 \\
\cline { 2 - 4 } & 95.12 & 4.88 & 100.00 \\
\cline { 2 - 4 } & 51.38 & 50.77 & 51.35 \\
\hline \multirow{4}{*}{ Total } & 48.84 & 2.50 & 51.35 \\
\cline { 2 - 4 } & 12,879 & 668 & 13,547 \\
\cline { 2 - 4 } & 95.07 & 4.93 & 100.00 \\
\cline { 2 - 4 } & 100.00 & 100.00 & 100.00 \\
\hline & 95.07 & 4.93 & 100.00 \\
\hline
\end{tabular}

Table 4

Prevalence of Obesity among Boys by Age Group

\begin{tabular}{|c|c|c|c|}
\hline \multirow{2}{*}{$\begin{array}{c}\text { Age-Group } \\
\text { (in years) }\end{array}$} & \multicolumn{3}{|c|}{ Obese } \\
\cline { 2 - 4 } & No & Yes & Total \\
\hline \multirow{4}{*}{$2-5$} & 6,845 & 360 & 7,205 \\
\cline { 2 - 4 } & 95.01 & 4.99 & 100.00 \\
\cline { 2 - 4 } & 48.80 & 48.86 & 48.81 \\
\cline { 2 - 4 } & 46.37 & 2.44 & 48.81 \\
\hline \multirow{4}{*}{$6-11$} & 7,181 & 377 & 7,558 \\
\cline { 2 - 4 } & 95.02 & 4.98 & 100.00 \\
\cline { 2 - 4 } & 51.20 & 51.14 & 51.19 \\
\hline \multirow{3}{*}{ Total } & 48.64 & 2.55 & 51.19 \\
\cline { 2 - 4 } & 14,027 & 736 & 14,763 \\
\cline { 2 - 4 } & 95.01 & 4.99 & 100.00 \\
\cline { 2 - 4 } & 100.00 & 100.00 & 100.00 \\
\hline
\end{tabular}


Table 5

Prevalence of Obesity among Children 2-11 Years by Poverty Status

\begin{tabular}{|c|c|c|c|}
\hline \multirow{3}{*}{$\begin{array}{c}\text { Below } \\
\text { poverty line }\end{array}$} & \multicolumn{3}{|c|}{ Obese } \\
\cline { 2 - 4 } & No & Yes & Total \\
\hline \multirow{4}{*}{ No } & 18,283 & 976 & 19,259 \\
\cline { 2 - 4 } & 94.93 & 5.07 & 100.00 \\
\cline { 2 - 4 } & 67.95 & 69.49 & 68.03 \\
\cline { 2 - 4 } & 64.58 & 3.45 & 68.03 \\
\hline \multirow{4}{*}{ Yes } & 8,622 & 429 & 9,051 \\
\cline { 2 - 4 } & 95.27 & 4.73 & 100.00 \\
\cline { 2 - 4 } & 32.05 & 30.51 & 31.97 \\
\hline \multirow{4}{*}{ Total } & 30.46 & 1.51 & 31.97 \\
\cline { 2 - 4 } & 26,905 & 1,405 & 28,310 \\
\cline { 2 - 4 } & 95.04 & 4.96 & 100.00 \\
\cline { 2 - 4 } & 100.00 & 100.00 & 100.00 \\
\hline
\end{tabular}

Table 6

Prevalence of Obesity among Children 2-11 Years by Caste

\begin{tabular}{|c|c|c|c|}
\hline \multirow{2}{*}{ Caste } & \multicolumn{3}{|c|}{ Obese } \\
\hline & No & Yes & Total \\
\hline \multirow{4}{*}{ SC } & 6,273 & 335 & 6,608 \\
\hline & 94.93 & 5.07 & 100.00 \\
\hline & 23.31 & 23.87 & 23.34 \\
\hline & 22.16 & 1.18 & 23.34 \\
\hline \multirow{4}{*}{ ST } & 2,049 & 100 & 2,149 \\
\hline & 95.34 & 4.66 & 100.00 \\
\hline & 7.62 & 7.13 & 7.59 \\
\hline & 7.24 & 0.35 & 7.59 \\
\hline \multirow{4}{*}{$\mathrm{OBC}$} & 9,868 & 359 & 10,226 \\
\hline & 96.49 & 3.51 & 100.00 \\
\hline & 36.67 & 25.54 & 36.12 \\
\hline & 34.86 & 1.27 & 36.12 \\
\hline \multirow{4}{*}{ Other } & 8,716 & 610 & 9,326 \\
\hline & 93.45 & 6.55 & 100.00 \\
\hline & 32.39 & 43.46 & 32.94 \\
\hline & 30.79 & 2.16 & 32.94 \\
\hline \multirow{4}{*}{ Total } & 26,905 & 1,405 & 28,310 \\
\hline & 95.04 & 4.96 & 100.00 \\
\hline & 100.00 & 100.00 & 100.00 \\
\hline & 95.04 & 4.96 & 100.00 \\
\hline
\end{tabular}


Table 7

Prevalence of Obesity among Children 2-11 Years by Location

\begin{tabular}{|c|c|c|c|}
\hline \multirow{3}{*}{ Location } & \multicolumn{3}{|c|}{ Obese } \\
\cline { 2 - 4 } & No & Yes & Total \\
\hline \multirow{4}{*}{ Rural } & 20,864 & 1,000 & 21,864 \\
\cline { 2 - 4 } & 95.43 & 4.57 & 100.00 \\
\cline { 2 - 4 } & 77.55 & 71.17 & 77.23 \\
\cline { 2 - 4 } & 73.70 & 3.53 & 77.23 \\
\hline \multirow{4}{*}{ Urban } & 5,485 & 385 & 5,870 \\
\cline { 2 - 4 } & 93.45 & 6.55 & 100.00 \\
\cline { 2 - 4 } & 20.39 & 27.38 & 20.73 \\
\hline \multirow{4}{*}{ Urban Slum } & 19.37 & 1.36 & 20.73 \\
\cline { 2 - 4 } & 556 & 20 & 576 \\
\cline { 2 - 4 } & 96.47 & 3.53 & 100.00 \\
\cline { 2 - 4 } & 2.07 & 1.45 & 2.04 \\
\hline \multirow{3}{*}{ Total } & 1.96 & 0.07 & 2.04 \\
\cline { 2 - 4 } & 26,905 & 1,405 & 28,310 \\
\cline { 2 - 4 } & 95.04 & 4.96 & 100.00 \\
\cline { 2 - 4 } & 100.00 & 100.00 & 100.00 \\
\cline { 2 - 4 } & 95.04 & 4.96 & 100.00 \\
\hline
\end{tabular}

Table 8

Prevalence of Obesity among Male Children 2-11 Years by Location

\begin{tabular}{|c|c|c|c|}
\hline \multirow{2}{*}{ Location } & \multicolumn{3}{|c|}{ Obese } \\
\hline & No & Yes & Total \\
\hline \multirow{4}{*}{ Rural } & 10,872 & 524 & 11,396 \\
\hline & 95.41 & 4.59 & 100.00 \\
\hline & 77.51 & 71.10 & 77.19 \\
\hline & 73.64 & 3.55 & 77.19 \\
\hline \multirow{4}{*}{ Urban } & 2,873 & 199 & 3,072 \\
\hline & 93.51 & 6.49 & 100.00 \\
\hline & 20.48 & 27.06 & 20.81 \\
\hline & 19.46 & 1.35 & 20.81 \\
\hline \multirow{4}{*}{$\begin{array}{l}\text { Urban } \\
\text { Slum }\end{array}$} & 282 & 14 & 296 \\
\hline & 95.42 & 4.58 & 100.00 \\
\hline & 2.01 & 1.84 & 2.00 \\
\hline & 1.91 & 0.09 & 2.00 \\
\hline \multirow{4}{*}{ Total } & 14,027 & 736 & 14,763 \\
\hline & 95.01 & 4.99 & 100.00 \\
\hline & 100.00 & 100.00 & 100.00 \\
\hline & 95.01 & 4.99 & 100.00 \\
\hline
\end{tabular}


Table 9

Prevalence of Obesity among Female Children 2-11 Years by Location

\begin{tabular}{|c|c|c|c|}
\hline \multirow{2}{*}{ Location } & \multicolumn{3}{|c|}{ Obese } \\
\hline & No & Yes & Total \\
\hline \multirow{4}{*}{ Rural } & 9,992 & 476 & 10,469 \\
\hline & 95.45 & 4.55 & 100.00 \\
\hline & 77.59 & 71.24 & 77.28 \\
\hline & 73.76 & 3.51 & 77.28 \\
\hline \multirow{4}{*}{ Urban } & 2,613 & 185 & 2,798 \\
\hline & 93.38 & 6.62 & 100.00 \\
\hline & 20.29 & 27.74 & 20.65 \\
\hline & 19.29 & 1.37 & 20.65 \\
\hline \multirow{4}{*}{ Urban Slum } & 274 & 7 & 281 \\
\hline & 97.57 & 2.43 & 100.00 \\
\hline & 2.13 & 1.02 & 2.07 \\
\hline & 2.02 & 0.05 & 2.07 \\
\hline \multirow{4}{*}{ Total } & 12879 & 668 & 13547 \\
\hline & 95.07 & 4.93 & 100.00 \\
\hline & 100.00 & 100.00 & 100.00 \\
\hline & 95.07 & 4.93 & 100.00 \\
\hline
\end{tabular}

Table 10

Obesity among Adults (>22 Years) by Gender

\begin{tabular}{|c|c|c|c|c|}
\hline \multirow{3}{*}{ Gender } & \multicolumn{4}{|c|}{ BM group } \\
\cline { 2 - 5 } & $0-25$ & $25-30$ & $>30$ & 582 \\
\hline \multirow{3}{*}{ Male } & 513 & 55 & 14 & 100.00 \\
\cline { 2 - 5 } & 88.07 & 9.49 & 1.49 & 1.93 \\
\cline { 2 - 5 } & 2.02 & 1.46 & 0.05 & 1.93 \\
\hline \multirow{3}{*}{ Female } & 1.70 & 0.18 & 941 & 29548 \\
\cline { 2 - 5 } & 24869 & 3738 & 3.18 & 100.00 \\
\cline { 2 - 5 } & 84.17 & 12.65 & 98.51 & 98.07 \\
\cline { 2 - 5 } & 97.98 & 98.54 & 3.12 & 98.07 \\
\hline \multirow{5}{*}{ Total } & 82.54 & 12.41 & 955 & 30130 \\
\hline & 25382 & 3793 & 3.17 & 100.00 \\
\cline { 2 - 5 } & 84.24 & 12.59 & 100.00 & 100.00 \\
\hline
\end{tabular}


Table 11

Obesity among Adult Males (>22 Years) by Age Group

\begin{tabular}{|c|c|c|c|c|}
\hline \multirow{2}{*}{$\begin{array}{l}\text { Age- Group } \\
\text { (in years) }\end{array}$} & \multicolumn{4}{|c|}{ BMI Group } \\
\hline & $0-25$ & $25-30$ & $>30$ & Total \\
\hline \multirow{4}{*}{$23-45$} & 305 & 29 & 7 & 340 \\
\hline & 89.51 & 8.55 & 1.94 & 100.00 \\
\hline & 71.92 & 63.79 & 56.15 & 70.76 \\
\hline & 63.34 & 6.05 & 1.37 & 70.76 \\
\hline \multirow{4}{*}{$>45$} & 119 & 17 & 5 & 141 \\
\hline & 84.59 & 11.75 & 3.66 & 100.00 \\
\hline & 28.08 & 36.21 & 43.85 & 29.24 \\
\hline & 24.73 & 3.44 & 1.07 & 29.24 \\
\hline \multirow{4}{*}{ Total } & 424 & 46 & 12 & 481 \\
\hline & 88.07 & 9.49 & 2.44 & 100.00 \\
\hline & 100.00 & 100.00 & 100.00 & 100.00 \\
\hline & 88.07 & 9.49 & 2.44 & 100.00 \\
\hline
\end{tabular}

Table 12

Obesity among Adult Females ( $>22$ Years) by Age Group

\begin{tabular}{|c|c|c|c|c|}
\hline \multirow{2}{*}{$\begin{array}{c}\text { Age- Group } \\
\text { (in years) }\end{array}$} & \multicolumn{4}{|c|}{ BM Group } \\
\cline { 2 - 5 } & $0-25$ & $25-30$ & $>30$ & Total \\
\hline \multirow{3}{*}{$23-45$} & 23,451 & 3,307 & 835 & 27,593 \\
\cline { 2 - 5 } & 84.99 & 11.99 & 3.03 & 100.00 \\
\cline { 2 - 5 } & 93.98 & 88.18 & 88.43 & 93.07 \\
\cline { 2 - 5 } & 79.09 & 11.16 & 2.82 & 93.07 \\
\hline \multirow{4}{*}{$>45$} & 1,503 & 443 & 109 & 2,056 \\
\cline { 2 - 5 } & 73.13 & 21.56 & 5.31 & 100.00 \\
\cline { 2 - 5 } & 6.02 & 11.82 & 11.57 & 6.93 \\
\hline \multirow{3}{*}{ Total } & 5.07 & 1.49 & 0.37 & 6.93 \\
\cline { 2 - 5 } & 24,954 & 3,751 & 944 & 29,649 \\
\cline { 2 - 5 } & 84.17 & 12.65 & 3.18 & 100.00 \\
\cline { 2 - 5 } & 100.00 & 100.00 & 100.00 & 100.00 \\
\hline & 84.17 & 12.65 & 3.18 & 100.00 \\
\hline
\end{tabular}


Table 13

Obesity among Adults ( $>22$ Years) by Poverty Status

\begin{tabular}{|c|c|c|c|c|}
\hline \multirow{2}{*}{$\begin{array}{c}\text { Below } \\
\text { poverty line }\end{array}$} & \multicolumn{4}{|c|}{ BMl group } \\
\cline { 2 - 5 } & $0-25$ & $25-30$ & $>30$ & Total \\
\hline \multirow{3}{*}{ No } & 19,286 & 3,330 & 871 & 23,487 \\
\cline { 2 - 5 } & 82.11 & 14.18 & 3.71 & 100.00 \\
\cline { 2 - 5 } & 75.98 & 87.79 & 91.20 & 77.95 \\
\hline \multirow{4}{*}{ Yes } & 64.01 & 11.05 & 2.89 & 77.95 \\
\cline { 2 - 5 } & 6,096 & 463 & 84 & 6,643 \\
\cline { 2 - 5 } & 91.76 & 6.97 & 1.27 & 100.00 \\
\cline { 2 - 5 } & 24.02 & 12.21 & 8.80 & 22.05 \\
\hline \multirow{4}{*}{ Total } & 20.23 & 1.54 & 0.28 & 22.05 \\
\cline { 2 - 5 } & 25,382 & 3,793 & 955 & 30,130 \\
\cline { 2 - 5 } & 84.24 & 12.59 & 3.17 & 100.00 \\
\cline { 2 - 5 } & 100.00 & 100.00 & 100.00 & 100.00 \\
\hline
\end{tabular}

Table 14

Obesity among Adults ( $>22$ Years) by Caste

\begin{tabular}{|c|c|c|c|c|}
\hline \multirow{2}{*}{ Caste } & \multicolumn{4}{|c|}{ BMl group } \\
\hline & $0-25$ & $25-30$ & $>30$ & Total \\
\hline \multirow{4}{*}{$\mathrm{SC}$} & 5,954 & 584 & 107 & 6,644 \\
\hline & 89.61 & 8.78 & 1.61 & 100.00 \\
\hline & 23.46 & 15.39 & 11.18 & 22.05 \\
\hline & 19.76 & 1.94 & 0.35 & 22.05 \\
\hline \multirow{4}{*}{ ST } & 2,024 & 133 & 25 & 2,182 \\
\hline & 92.75 & 6.08 & 1.16 & 100.00 \\
\hline & 7.97 & 3.50 & 2.65 & 7.24 \\
\hline & 6.72 & 0.44 & 0.08 & 7.24 \\
\hline \multirow{4}{*}{$\mathrm{OBC}$} & 9,158 & 1,241 & 294 & 10,693 \\
\hline & 85.65 & 11.61 & 2.75 & 100.00 \\
\hline & 36.08 & 32.72 & 30.76 & 35.49 \\
\hline & 30.40 & 4.12 & 0.97 & 35.49 \\
\hline \multirow{4}{*}{ Other } & 8,246 & 1,836 & 529 & 10,610 \\
\hline & 77.71 & 17.30 & 4.99 & 100.00 \\
\hline & 32.49 & 48.39 & 55.41 & 35.22 \\
\hline & 27.37 & 6.09 & 1.76 & 35.22 \\
\hline \multirow{4}{*}{ Total } & 25,382 & 3,793 & 955 & 30,130 \\
\hline & 84.24 & 12.59 & 3.17 & 100.00 \\
\hline & 100.00 & 100.00 & 100.00 & 100.00 \\
\hline & 84.24 & 12.59 & 3.17 & 100.00 \\
\hline
\end{tabular}


Table 15

Obesity among Adults (>22 Years) by Location

\begin{tabular}{|c|c|c|c|c|}
\hline \multirow{3}{*}{ Location } & \multicolumn{4}{|c|}{ BMl group } \\
\cline { 2 - 5 } & $0-25$ & $25-30$ & $>30$ & Total \\
\hline \multirow{3}{*}{ Rural } & 19,058 & 1,933 & 366 & 21,357 \\
\cline { 2 - 5 } & 89.23 & 9.05 & 1.72 & 100.00 \\
\cline { 2 - 5 } & 75.09 & 50.96 & 38.36 & 70.88 \\
\hline \multirow{4}{*}{ Urban } & 63.25 & 6.42 & 1.22 & 70.88 \\
\cline { 2 - 5 } & 5,863 & 1,779 & 558 & 8,199 \\
\cline { 2 - 5 } & 71.50 & 21.70 & 6.80 & 100.00 \\
\hline \multirow{4}{*}{ Urban Slum } & 23.10 & 46.90 & 58.39 & 27.21 \\
\cline { 2 - 5 } & 19.46 & 5.90 & 1.85 & 27.21 \\
\cline { 2 - 5 } & 461 & 81 & 31 & 574 \\
\cline { 2 - 5 } & 80.43 & 14.16 & 5.41 & 100.00 \\
\hline \multirow{4}{*}{ Total } & 1.82 & 2.14 & 3.25 & 1.90 \\
\hline & 1.53 & 0.27 & 0.10 & 1.90 \\
\cline { 2 - 5 } & 25,382 & 3,793 & 955 & 100.00 \\
\cline { 2 - 5 } & 84.24 & 12.59 & 3.17 & 100.00 \\
\hline
\end{tabular}


Table 16

Factors Associated with Obesity among Children of age group 2-11 years: Probit Analysis

\begin{tabular}{|c|c|c|}
\hline Age & $0.538^{\star \star \star}(13.72)$ & $0.015^{\star \star \star}(11.49)$ \\
\hline Age-squared & $-0.012^{\star \star \star}(-4.23)$ & $-0.0003^{\star * *}(-4.16)$ \\
\hline $\mathrm{SC}$ & $0.052(0.94)$ & $0.001(0.91)$ \\
\hline ST & $0.028(0.27)$ & $0.001(0.26)$ \\
\hline $\mathrm{OBC}$ & $-0.159^{* \star *}(-3.19)$ & $-0.004^{\star \star \star}(-3.290$ \\
\hline Gender & $-0.059(-1.53)$ & $-0.002(-1.53)$ \\
\hline Highest adult male education: Primary & $0.001(0.02)$ & $0.000(0.02)$ \\
\hline Highest adult male education: Middle & $0.099(1.54)$ & $0.003(1.48)$ \\
\hline Highest adult male education: Secondary and above & $0.071(0.81)$ & $0.002(0.77)$ \\
\hline Highest Female education: Primary & $-0.019(-0.3)$ & $-0.001(-0.30)$ \\
\hline Highest Female education: Middle & $-0.079(-1.23)$ & $-0.002(-1.29)$ \\
\hline Highest Female education: Secondary and above & $-0.074(-0.79)$ & $-0.002(-0.85)$ \\
\hline Household toilet & $0.150^{* \star *}(3.03)$ & $0.004^{\star \star *}(2.82)$ \\
\hline Vent in cooking place & $0.004(0.08)$ & $0.000(0.08)$ \\
\hline Access to safe drinking water & $0.554^{\star \star *}(3.01)$ & $0.009^{\star * *}(6.08)$ \\
\hline Rural areas & $-0.129 * *(-2.03)$ & $-0.004^{*}(-1.90)$ \\
\hline Urban metros & $0.271^{* * *(3.78)}$ & $0.010^{* * *}(2.96)$ \\
\hline Household size & $0.006(0.28)$ & $0.000(0.28)$ \\
\hline Household size squared & $0.001(1.03)$ & $0.000(1.03)$ \\
\hline Nuclear family & $0.007(0.06)$ & $0.000(0.06)$ \\
\hline Log PCME (IV) & $0.395^{\star \star \star}(3.80)$ & $0.011^{\star \star \star}(3.80)$ \\
\hline Height (Z score) & $-2.324^{\star \star \star}(-8.43)$ & $-0.064^{\star \star *}(-8.38)$ \\
\hline Log PCME x Height & $0.118^{* \star *}(2.80)$ & $0.003^{* * *}(2.85)$ \\
\hline Whether mother has most say in cooking? (Predicted) & $-0.191(-0.42)$ & $-0.005(-0.42)$ \\
\hline Price ratio: Cereal to Pulse & $-0.354 *(-1.68)$ & $-0.010 *(-1.68)$ \\
\hline Price ratio: Cereal to Milk & $-0.164 w(-1.61)$ & $-0.005 w(-1.61)$ \\
\hline Price ratio: Cereal to Meat & $0.673^{\star \star *}(2.68)$ & $0.019 * * *(2.66)$ \\
\hline Price ratio: Cereal to Egg & $-0.611 *(-1.69)$ & $-0.017 *(-1.69)$ \\
\hline Price ratio: Cereal to Vegetable & $-0.157^{\star \star *}(-3.08)$ & $-0.004^{* * *(-3.06)}$ \\
\hline Price ratio: Cereal to Oil & $-1.881^{* *}(-2.40)$ & $-0.052^{\star \star}(-2.40)$ \\
\hline Price ratio: Cereal to Sugar & $1.278^{\star \star \star}(4.69)$ & $0.035^{\star \star *}(4.62)$ \\
\hline Constant & $-7.947^{\star \star \star}(-9.80)$ & \\
\hline Number of observations & 22971 & \\
\hline Likelihood Ratio Chi-square & $4062.17^{\star \star \star}$ & \\
\hline Pseudo R-square & 0.4547 & \\
\hline Log likelihood & -2435.43 & \\
\hline Predicted probability & & 0.010 \\
\hline
\end{tabular}

Note: ${ }^{* * *, * *, *}$ refer to significance at the $1 \%, 5 \%$ and $10 \%$ level, respectively; and $w$ denotes weakly significant (>10 $\%$ level). All price ratios are at the PSU level. 
Table 17

Factors Associated with Obesity among Adults $>22$ years: Probit Analysis

\begin{tabular}{|c|c|c|}
\hline Explanatory variables & Coeff (z-value) & Marginal effect (z-value) \\
\hline Age & $0.108^{\star \star \star}(4.67)$ & $0.005^{\star \star *}(4.72)$ \\
\hline Age-squared & $-0.001^{\star \star \star}(-3.66)$ & $-0.0001^{\star \star \star}(-3.69)$ \\
\hline SC & $-0.215^{\star \star *}(-4.04)$ & $-0.009^{\star \star *}(-4.54)$ \\
\hline ST & $-0.448^{\star \star \star}(-3.36)$ & $-0.014^{\star * *}(-5.49)$ \\
\hline OBC & $-0.098^{\star \star}(-2.48)$ & $-0.004^{\star * *}(-2.54)$ \\
\hline Gender $^{1}$ & $0.084(0.61)$ & $0.004(0.66)$ \\
\hline Years of education & $0.032^{\star \star *}(2.91)$ & $0.001 * * *(2.92)$ \\
\hline Square of years of education & $-0.001 *(-1.64)$ & $-0.0001 *(-1.65)$ \\
\hline Household toilet & $0.282^{\star \star \star}(6.51)$ & $0.014 * *(6.15)$ \\
\hline Vent in cooking place & $-0.002(-0.06)$ & $0.000(-0.06)$ \\
\hline Access to safe drinking water & $-0.119(-1.19)$ & $-0.006(-1.06)$ \\
\hline Rural areas & $-0.286^{\star \star \star}(-6.48)$ & $-0.015^{\star \star \star}(-5.86)$ \\
\hline Urban metros & $-0.200 * * \star(-4.01)$ & $-0.008^{* * *}(-4.64)$ \\
\hline Marital status: Married & $0.007(0.08)$ & $0.000(0.08)$ \\
\hline Nuclear family & $-0.010(-0.28)$ & $0.000(-0.28)$ \\
\hline Log PCME (IV) & $0.282^{\star \star \star}(4.35)$ & $0.013^{\star \star *}(4.36)$ \\
\hline Height (Z score) & $-0.193(-1.13)$ & $-0.009(-1.13)$ \\
\hline Log PCME x Height & $0.002(0.06)$ & $0.000(0.06)$ \\
\hline Price ratio: Cereal to Pulse & $-0.280 *(-1.64)$ & $-0.013^{*}(-1.64)$ \\
\hline Price ratio: Cereal to Milk & $0.178^{\star \star}(2.34)$ & $0.008^{\star \star}(2.34)$ \\
\hline Price ratio: Cereal to Meat & $-0.453^{*}(-1.70)$ & $-0.021 *(-1.70)$ \\
\hline Price ratio: Cereal to Egg & $0.274(0.95)$ & $0.013(0.95)$ \\
\hline Price ratio: Cereal to Vegetable & $0.017(0.40)$ & $0.001(0.40)$ \\
\hline Price ratio: Cereal to Oil & $0.662(1.09)$ & $0.031(1.09)$ \\
\hline Price ratio: Cereal to Sugar & $0.146(0.67)$ & $0.007(0.67)$ \\
\hline Constant & $-6.247^{\star \star \star}(-10.24)$ & \\
\hline Number of observations & 25283 & \\
\hline Likelihood Ratio Chi-square & $968.56^{\star \star \star}$ & \\
\hline Pseudo R-square & 0.1333 & \\
\hline Log likelihood & -3147.93 & \\
\hline Predicted probability & & 0.019 \\
\hline
\end{tabular}

Note: $* \star \star \star * *$, , refer to significance at the $1 \%, 5 \%$ and $10 \%$ level, respectively; and w denotes weakly significant (>10 \% level). All price ratios are at the PSU level.

1. The gender effect cannot be taken at face value given the lop-sided female-male composition of adults in the sample. 
Table 18

Factors Associated with Obesity among Adults $>22$ years: Probit Analysis

\begin{tabular}{|c|c|c|}
\hline Explanatory variables & Coeff (z-value) & Marginal effect (z-value) \\
\hline Age & $0.098^{* * *(4.44)}$ & $0.005^{\star * *}(4.47)$ \\
\hline Age-squared & $-0.001^{* \star *}(-3.39)$ & $-0.0001^{* * *}(-3.41)$ \\
\hline SC & $-0.204^{\star * *}(-3.89)$ & $-0.009 * \star *(-4.35)$ \\
\hline ST & $-0.408^{\star \star \star}(-3.09)$ & $-0.014^{\star \star *}(-4.78)$ \\
\hline $\mathrm{OBC}$ & $-0.094^{\star \star}(-2.42)$ & $-0.005^{\star \star}(-2.47)$ \\
\hline Gender $^{1}$ & $0.180(1.32)$ & $0.008 w(1.6)$ \\
\hline Years of education & $0.025 * \star(2.23)$ & $0.001 *(2.22)$ \\
\hline Square of years of education & $-0.001(-0.82)$ & $0.000(-0.82)$ \\
\hline Household toilet & $0.253^{\star \star *}(5.95)$ & $0.013^{\star * *}(5.65)$ \\
\hline Vent in cooking place & $-0.009(-0.25)$ & $0.000(-0.25)$ \\
\hline Safe drinking water & $-0.127(-1.29)$ & $-0.007(-1.15)$ \\
\hline Rural Areas & $-0.283^{\star \star *}(-6.53)$ & $-0.016^{\star \star *}(-5.93)$ \\
\hline Urban metros & $-0.172^{\star \star \star}(-3.46)$ & $-0.008^{\star \star *}(-3.92)$ \\
\hline Marital status: Married & $0.013(0.15)$ & $0.001(0.15)$ \\
\hline Nuclear family & $-0.014(-0.38)$ & $-0.001(-0.38)$ \\
\hline Log PCME (IV) & $1.842^{\star}(1.69)$ & $0.093^{*}(1.71)$ \\
\hline Square of Log PCME (IV) & $-0.120(-1.47)$ & $-0.006(-1.48)$ \\
\hline Price ratio: Cereal to Pulse & $-0.211(-1.27)$ & $-0.011(-1.27)$ \\
\hline Price ratio: Cereal to Milk & $0.148 * *(1.97)$ & $0.007^{\star \star}(1.97)$ \\
\hline Price ratio: Cereal to Meat & $-0.397 w(-1.54)$ & $-0.020(-1.54)$ \\
\hline Price ratio: Cereal to Egg & $0.239(0.85)$ & $0.012(0.85)$ \\
\hline Price ratio: Cereal to Vegetable & $0.042(1.01)$ & $0.002(1.01)$ \\
\hline Price ratio: Cereal to Oil & $0.389(0.66)$ & $0.020(0.66)$ \\
\hline Price ratio: Cereal to Sugar & $0.165(0.77)$ & $0.008(0.77)$ \\
\hline Constant & $-11.193^{\star \star \star}(-3.05)$ & \\
\hline Number of obs & 25283 & \\
\hline Likelihood Ratio Chi-square & $767.17^{\star \star \star}$ & \\
\hline Pseudo R-square & 0.1056 & \\
\hline Log likelihood & -3248.62 & \\
\hline Predicted probability & & 0.021 \\
\hline
\end{tabular}

Note: $* \star \star, * *, *$ and refer to significance at the $1 \%, 5 \%, 10 \%$ levels, respectively; w denotes weak significance at $>10 \%$ level. All price ratios are at the PSU level.

1. The gender effect cannot be taken at face value given the lop-sided female-male composition of adults in the sample. 


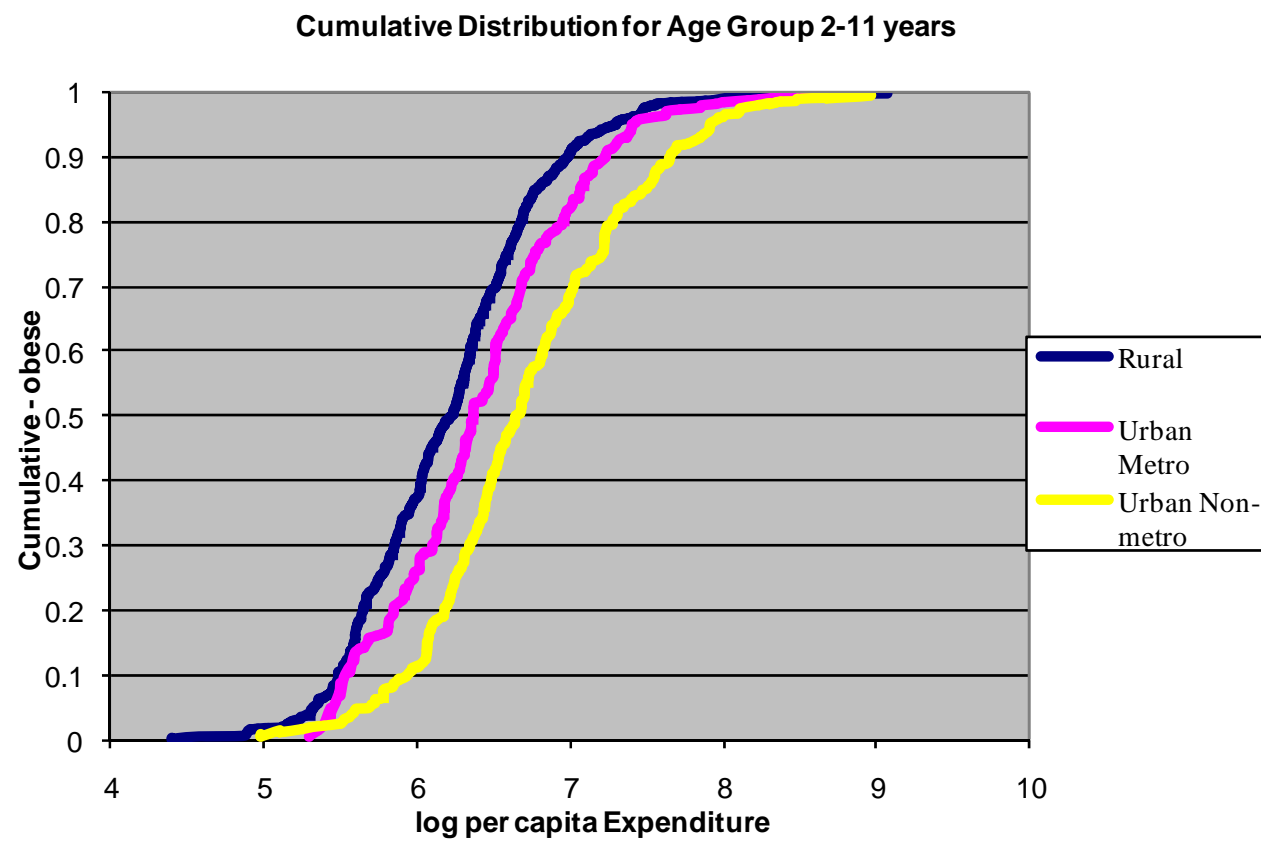

Figure 1: Cumulative Distribution of Obese Children 2-11 years by Expenditure

Cumulative Distribution for Age Group $>22$

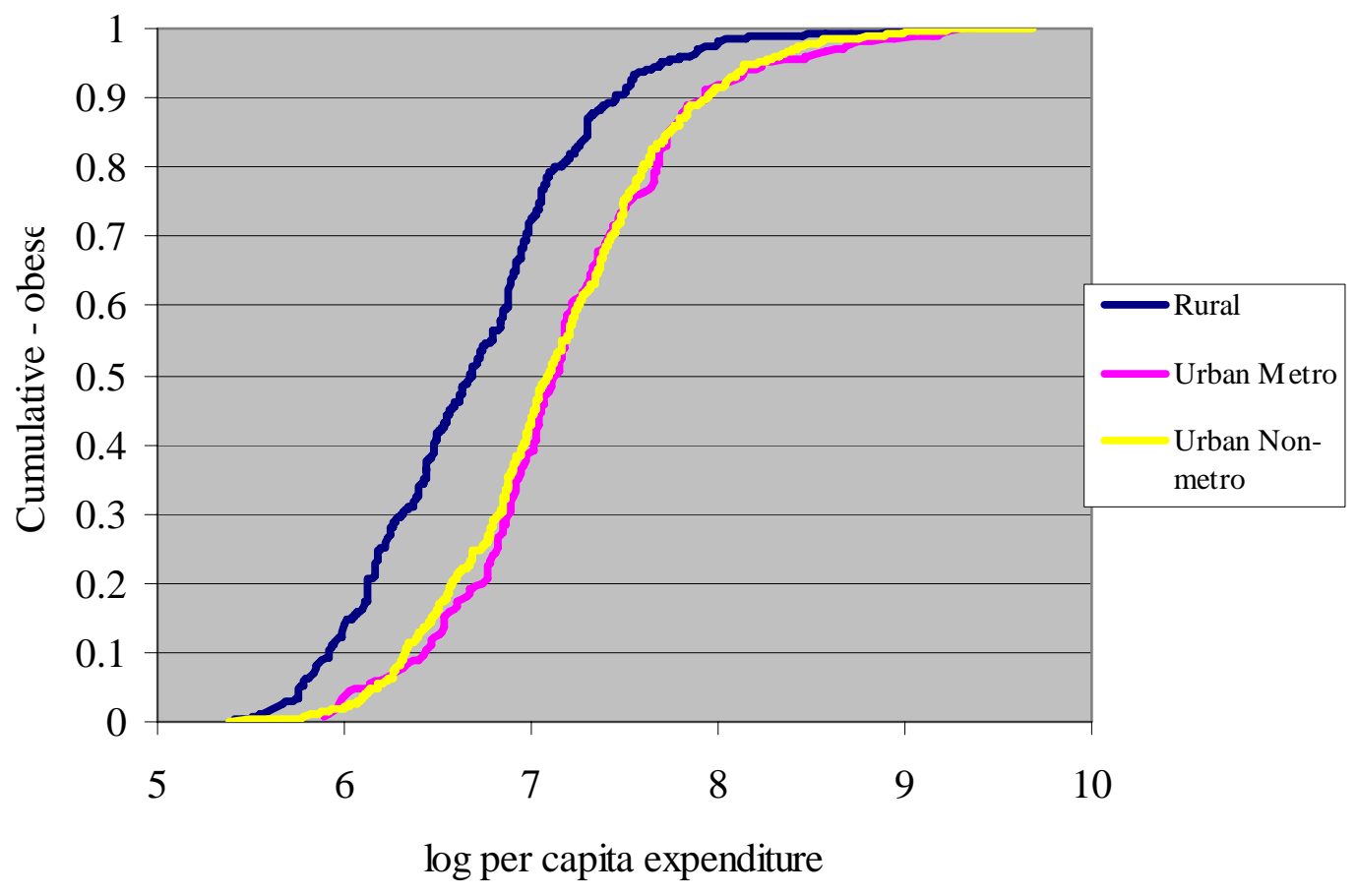

Figure 2 Cumulative Distribution of Obese Adults by Expenditure 
Table A.1

Definitions of Variables Used in the Analysis

\begin{tabular}{|c|c|}
\hline Variable & Definition \\
\hline \multicolumn{2}{|r|}{ Dependent variables } \\
\hline Obesity: children & $\begin{array}{l}=1 \text { if children of age group } 2-11 \text { years are obese } \\
\text { (BMI exceeds that of the } 95^{\text {th }} \text { percentile), } 0 \text { otherwise }\end{array}$ \\
\hline Obesity: adult & $=1$ if a person $>22$ years has $\mathrm{BMI}>30,0$ otherwise \\
\hline \multicolumn{2}{|r|}{ Explanatory variables } \\
\hline Age & Age (in years) \\
\hline Age-squared & Square of the age \\
\hline Height & Z score \\
\hline SC & $=1$ if social group is SC, 0 otherwise \\
\hline ST & $=1$ if social group is ST,0 otherwise \\
\hline OBC & $=1$ if social group is $\mathrm{OBC}, 0$ otherwise \\
\hline Others (reference) & Omitted group \\
\hline Gender & $=1$ if female, 0 if male \\
\hline Highest adult male education: Primary & $=1$ if highest adult male education is primary, 0 otherwise \\
\hline Highest adult male education: Middle & $=1$ if highest adult male education is middle school,0 otherwise \\
\hline Highest adult male education: Secondary \& above & $=1$ if highest adult male education is secondary and above, 0 otherwise \\
\hline Highest adult male education: illiterate (reference) & Omitted group \\
\hline Highest Female education: Primary & $=1$ if highest adult female education is primary, 0 otherwise \\
\hline Highest Female education: Middle & $=1$ if highest adult female education is middle school,0 otherwise \\
\hline Highest Female education: Secondary \& above & $=1$ if highest adult female education is secondary and above, 0 otherwise \\
\hline Highest Female education: illiterate (reference) & Omitted group \\
\hline Years of education & Number of years completed in education \\
\hline Square of years of education & Square of years of education \\
\hline Household toilet & $=1$ if household has toilet, 0 otherwise \\
\hline Vent in cooking place & $=1$ if kitchen has vent, 0 otherwise \\
\hline Access to safe drinking water & $=1$ if drinking water source safe \\
\hline Rural Areas & $=1$ if Rural, 0 otherwise \\
\hline Urban metros & $=1$ if Metro, 0 otherwise \\
\hline Non-metro urban (reference) & Omitted group \\
\hline Household size & Number of household members \\
\hline Household size squared & Household size squared \\
\hline Marital status: Married & $=1$ if a person is married, 0 otherwise \\
\hline Nuclear family & $=1$ if family is nuclear, 0 otherwise \\
\hline $\log$ PCME (IV) ${ }^{1}$ & Log of per capita monthly expenditure (predicted-) \\
\hline Square of Log PCME (IV) & Square of (predicted) log of per capita monthly expenditure \\
\hline Log PCME x Height & Interaction of log of per capita monthly expenditure (predicted) with height (z-score) \\
\hline Whether mother has most say in cooking? (IV) ${ }^{2}$ & Predicted value of whether mother has most say in cooking \\
\hline Price ratio: Cereal to Pulse ${ }^{3}$ & Price ratio of cereal to pulse \\
\hline Price ratio: Cereal to Milk & Price ratio of cereal to milk \\
\hline Price ratio: Cereal to Meat & Price ratio of cereal to meat \\
\hline Price ratio: Cereal to Egg & Price ratio of cereal to egg \\
\hline Price ratio: Cereal to Vegetable & Price ratio of cereal to vegetable \\
\hline Price ratio: Cereal to Oil & Price ratio of cereal to oil \\
\hline Price ratio: Cereal to Sugar & Price ratio of cereal to sugar \\
\hline
\end{tabular}

1. Details will be furnished on request.

2. For details, see Gaiha et al. (2009).

3. All price ratios are at the PSU level. 